Article

\title{
Infection with Leishmania (Leishmania) infantum Changes the Morphology and Myenteric Neurons of the Jejunum of Golden Hamsters
}

\author{
Sarah Kymberly Santos de Lima ${ }^{1} \mathbb{D}^{\mathbb{D}}$, Italo Novais Cavallone ${ }^{1}{ }^{(\mathbb{D}}$, Karine Soares Oliveira ${ }^{1}$, \\ Luiz Felipe Domingues Passero ${ }^{1}{ }^{1}$, Márcia Dalastra Laurenti ${ }^{2}{ }^{10}$, Jéssica Adriana Jesus ${ }^{2}$, \\ Gabriela Pustiglione Marinsek ${ }^{1}$, Thaís Martins Chucri ${ }^{1}$ and Renata de Britto Mari ${ }^{1, *}$ (i)
}

1 Department of Biological and Environmental Sciences, São Paulo State University-UNESP, São Vicente 11330-900, Brazil; sarah_melchert@hotmail.com (S.K.S.d.L.); id.cavallone@gmail.com (I.N.C.); karine.soaresoliveira11@gmail.com (K.S.O.); felipe.passero@unesp.br (L.F.D.P.); gabriela.marinsek@unesp.br (G.P.M.); thaischucri@uol.com.br (T.M.C.)

2 Laboratory of Pathology and Infectious Diseases, Department of Pathology/FMUSP, São Paulo 01246-903, Brazil; mdlauren@usp.br (M.D.L.); jessica.dolly@hotmail.com (J.A.J.)

* Correspondence: renata.mari@unesp.br; Tel.: +55-(13)-3569-7143

Citation: de Lima, S.K.S.; Cavallone, I.N.; Oliveira, K.S.; Passero, L.F.D.; Laurenti, M.D.; Jesus, J.A.; Marinsek, G.P.; Chucri, T.M.; Mari, R.d.B. Infection with Leishmania (Leishmania) infantum Changes the Morphology and Myenteric Neurons of the Jejunum of Golden Hamsters Parasitologia 2021, 1, 225-237. https://doi.org/10.3390/ parasitologia1040024

Academic Editor: Geoff Hide

Received: 2 September 2021

Accepted: 16 October 2021

Published: 20 October 2021

Publisher's Note: MDPI stays neutral with regard to jurisdictional claims in published maps and institutional affiliations.

Copyright: (c) 2021 by the authors. Licensee MDPI, Basel, Switzerland. This article is an open access article distributed under the terms and conditions of the Creative Commons Attribution (CC BY) license (https:/ creativecommons.org/licenses/by/ $4.0 /)$
Abstract: Visceral leishmaniasis (VL) is one of the most severe clinical manifestations of leishmaniasis as it leads to death in $90 \%$ of untreated cases. The liver, spleen and bone marrows are the organs most affected; however, Leishmania parasites are able to reach the intestines where the gut-associated lymphoid tissue (GALT) is located. Under physiological conditions, the gastrointestinal tract and GALT interact with the enteric nervous system (SNE); however, there are no studies exploring the modulatory role of Leishmania (Leishmania) infantum in the intestines. Thus, this work aimed to investigate the parasitism, stratigraphy, and morphological changes in the myenteric plexus of golden hamsters infected with $L$. (L.) infantum. The animals were infected intraperitoneally, and the parasite load was evaluated in the spleen, the liver, and the jejunum. The stratigraphic evaluation and the quantitative and morphometric analyses of NADH-dp and NADPH-dp myenteric neurons were studied at 30-, 60-, and 90-days post-infection (DPI). Parasites in the spleen, the liver, and the jejunum increased during the progression of the infection. Stratigraphy studies showed a significant hypertrophy of the villi and the crypts associated with the increased intraepithelial lymphocytes that were observed in the jejunum of the infected animals. In addition, mucosal atrophy associated with a reduction in $\mathrm{AB}+$ and PAS+ goblet cells was observed at $60 \mathrm{DPI}$ and 90 DPI. These morphological changes were associated with an atrophy of the cell profile from NADPH-dp myenteric neurons. Furthermore, a significant decrease in the densities of this neuron population was observed in the chronic phase of the infection. This study suggests that $L$. (L.) infantum parasites are able to alter the morphology and innervation of the jejunum in golden hamsters.

Keywords: visceral leishmaniasis; NAPH-dp; NADH-dp; intestinal barrier; inflammation

\section{Introduction}

Leishmaniasis is an infectious disease distributed throughout the world and is caused by the parasitic protozoan of the genus Leishmania, which infects wild and domestic animals as well as humans [1,2]. Among the clinical manifestations of leishmaniasis, visceral leishmaniasis (VL) is one of the most severe, especially in patients with underlying diseases such as HIV or other medical conditions that affect immunity [3,4]. The main organs affected by VL are associated with the immune system where phagocytic cells can be found, such as the spleen, the liver, the lymph nodes, and the bone marrow [5-7]. However, other organs can be affected by VL, and in some cases, classical clinical signs observed during infection indicate that the parasites have an impact on the homeostasis of other organs. For example, weight loss, anemia, and vomiting also are clinical signs associated with intestinal 
dysfunction that compound the severity of VL $[8,9]$ and also suggest that the parasite infection may affect the gastrointestinal tract (GIT). In natural infections, amastigote forms were detected in the gut of dogs infected with Leishmania infantum, especially in the lamina propria of the duodenum, the jejunum, and the ileum, and the local inflammatory responses were associated with the proliferation of the parasites [10]. The impact of these parasites on the enteric nervous system was not assessed.

The gastrointestinal tract (GIT) is a series of organs that include the intestines. In general, the small intestine is divided into three segments, the duodenum, the jejunum, and the ileum, and all of which have absorption as their main function. These segments display different anatomical, histological, and physiological specificities. Histologically, the small intestine is divided into layers: mucosa, mucosal muscle, submucosa, the inner and outer tunica muscularis, and the serous layer, which is the outermost layer of the organ [11,12].

The mucosal layer is composed of stem cells that originate from the crypts. They are differentiated into four types of epithelial cells that are organized along the villi and constitute the epithelium and the epithelial barrier [13-15]. Anatomically, the jejunum has villi and crypts in greater quantity and length, as compared to other segments of the small intestine [16], suggesting that this segment has a fundamental importance in nutrient absorption. It also has a thicker intestinal barrier lining its surface, which interacts with the external environment through the intestinal lumen and microbiota, selective permeability, antigen recognition, and effective immune responses [17-19].

Inside the villi is the lamina propria, which plays a fundamental role in the intestine due to its vascularization, and it is considered the gateway for immune cells to reach the organ. Through the accumulation of leukocytes in this area, the so-called gut-associated lymphatic tissue-GALT_acts in the development of immune responses against pathogens as well as in tissue repair $[20,21]$.

In the submucosal layer, we find the myenteric and submucosal plexus with a network of unmyelinated nerve fibers and ganglion cells. Between the muscle layers sits the myenteric plexus that has cell bodies of postganglionic parasympathetic neurons and neurons of the enteric nervous system (ENS) that control the GIT [22-24]. Enteric neurons have several specificities including phenotypic plasticity that may be altered in response to pathogens and serves as a mechanism of adaptive response to the damage produced by the pathogen [25-27].

Several studies have shown phenotypic plasticity through the assessment of density and neuronal morphometry in intestinal parasite infections [28-30]. In experimental infections caused by Leishmania (Viannia) braziliensis, a parasite that causes cutaneous leishmaniasis, hypertrophy of the cellular profile of myenteric plexus neurons was observed, suggesting an increase in their metabolic activity as an adaptation mechanism [31].

Histological changes in the intestines have been reported in experimental infections caused by Leishmania (Viannia) braziliensis in murine models and emphasized the hypertrophy of the villi and the crypts as well as the increase in inflammatory infiltrates in the submucosa and in the myenteric plexus ganglia, characterizing ganglionitis in infected animals [32]. Additionally, an intense inflammatory reaction associated with epithelial injury, distortion and loss of crypts, and fibrosis in the lamina propria was verified in the jejunum and the colon of dogs infected with Leishmania infantum [21,33], suggesting that Leishmania infantum is able to infect, spread, and change the architecture of the intestines.

Considering the physiological and immunological importance of the jejunum, this manuscript aimed to analyze the morphological and quantitative changes in neurons of the myenteric plexus. The population of metabolically active neurons (NADH-dp) was analyzed in order to mark the working neurons, and the nitrergic subpopulation (NADPHdp) presented neurons that express nitric oxide as a neurotransmitter and control GIT motility in the myenteric plexus. Neuronal assessments were associated with the parasite load and histopathological changes in the jejunum of golden hamsters (Mesocricetus auratus) experimentally infected by Leishmania. (L.) infantum. 


\section{Results}

\subsection{Parasite Load}

Parasite load analyses in the spleen and liver showed a significant increase in amastigote forms during the evolution of the infection (Figure 1). Similarly, a significant increase in the parasite load was observed in the jejunum during the progression of the VL infection, but in a smaller proportion than observed in the spleen and the liver $(p<0.05)$. No deaths were recorded before $90 \mathrm{DPI}$.

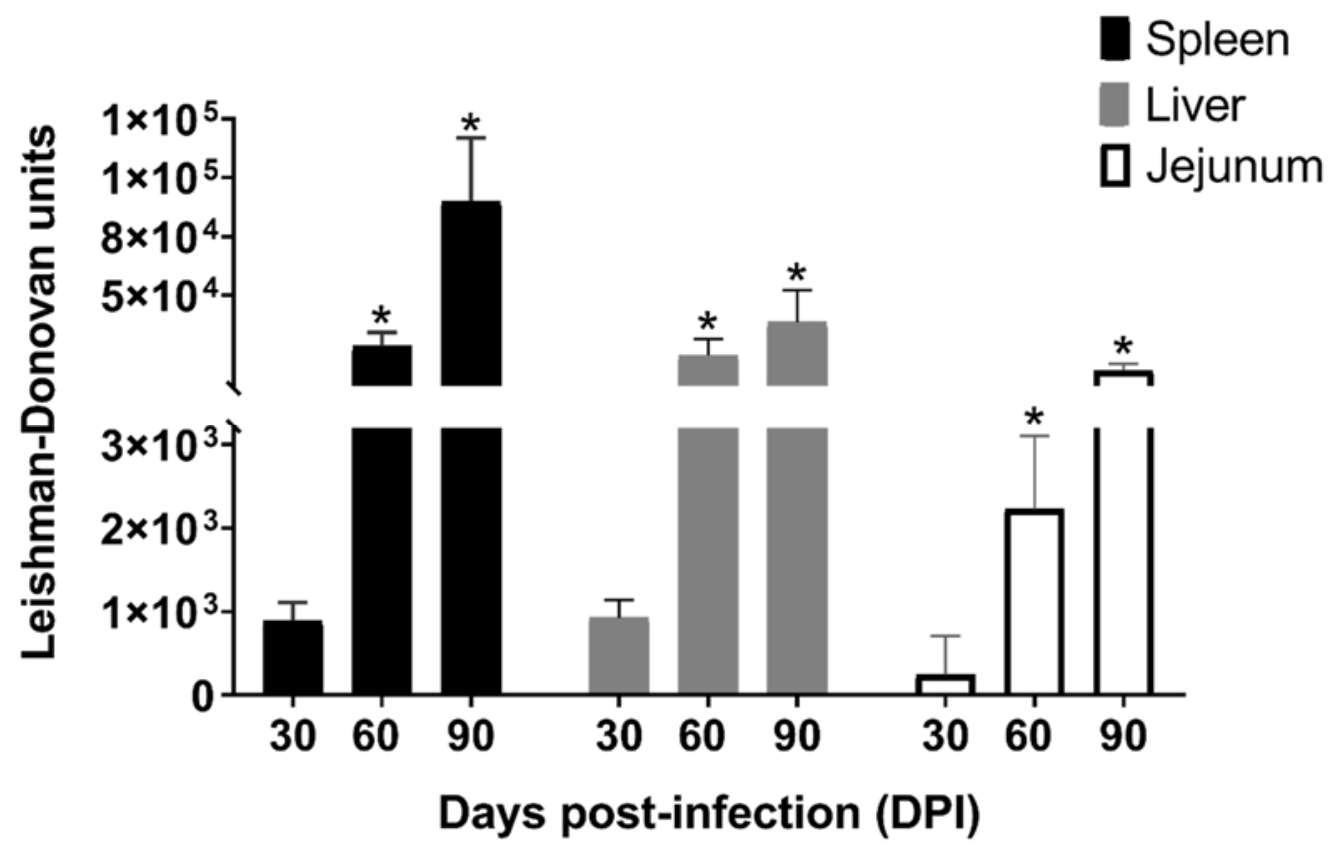

Figure 1. Parasite load in the spleen, the liver, and the jejunum, expressed by Leishmania-Donovan units (LDU) at 30-, 60-, and 90-days post-infection (DPI). ${ }^{*} p<0.05$, as compared to the parasite load from animals infected at 30 DPI in each organ.

\subsection{Neuronal Density and Infection Progression of NADH-dp and NADPH-dp}

In the quantitative neuronal analysis, it was observed that NADH-dp populations (Figure 2A-C) were similar in the control and infected animals. The nitrergic subpopulation showed a slight reduction in the evolution of the infection at $90 \mathrm{DPI}$, as compared to the beginning of the infection (30 DPI) (Figure 2E).

\subsection{Morphometry and Infection Progression of NADH-dp and NADPH-dp Neurons}

Following the quantitative evaluation, the morphology of the neurons was evaluated. With respect to the neuronal morphology of NADH-dp neurons, no significant differences were observed in the experimental and control groups (Figure 3A-C). In the NADPH-dp subpopulation, a significant reduction in the cellular profile was observed at 90 DPI in the experimental group in comparison to the control group (Figure 3D). Despite this, no change in relation to the comparison between the experimental animals was evidenced (Figure 3E,F). 

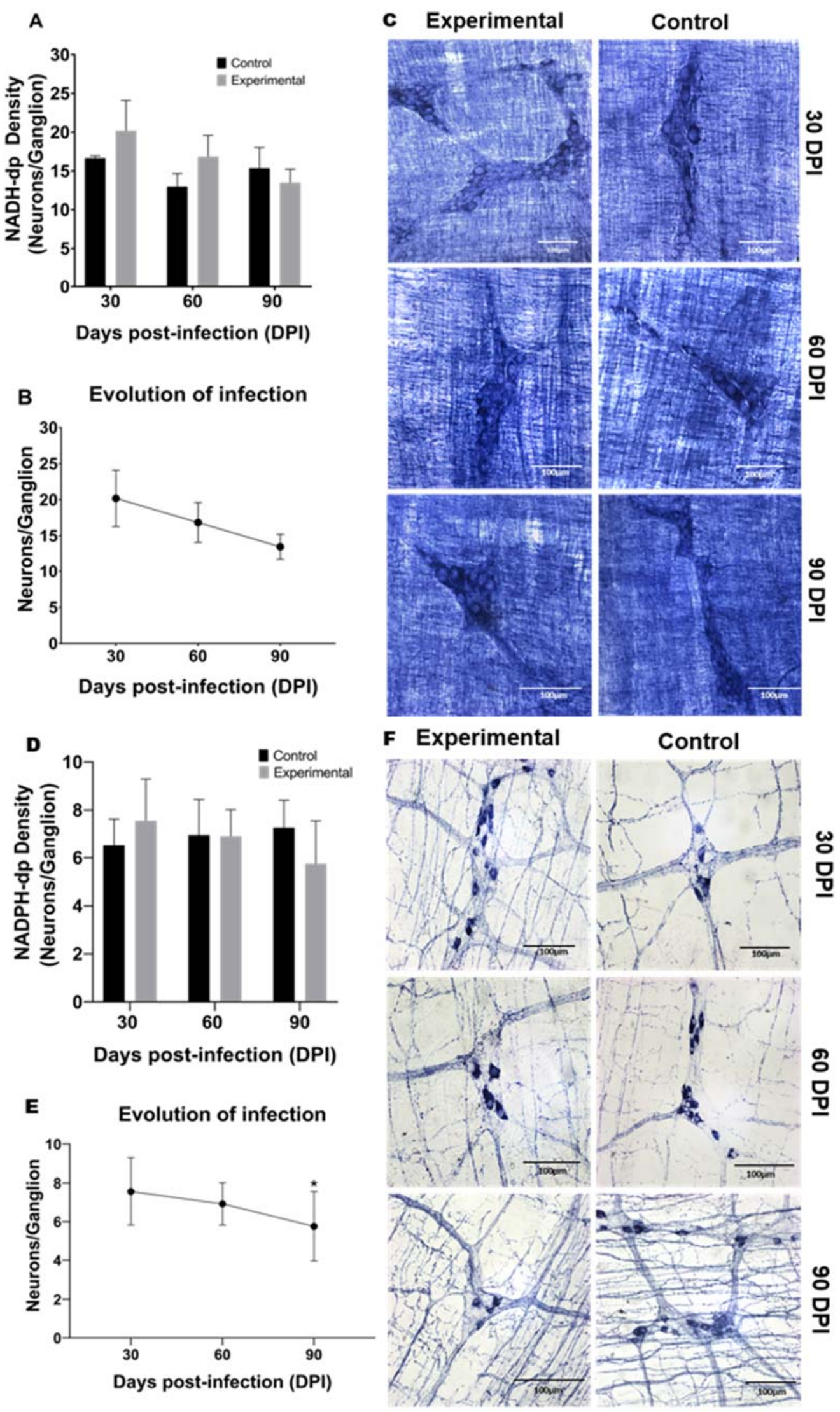

Figure 2. Population neuron density of NADH-dp (A) and NADPH-dp (D). Evolution of infection in experimental animals by NADH-dp (B) and NADPH-dp (E) neurons. Photomicrography of NADH-dp (C) and NADPH-dp (F) neurons at 30-, 60-, and 90-days post-infection (DPI). * $p<0.05$, as compared to evolution of infection at $30 \mathrm{DPI}$. 

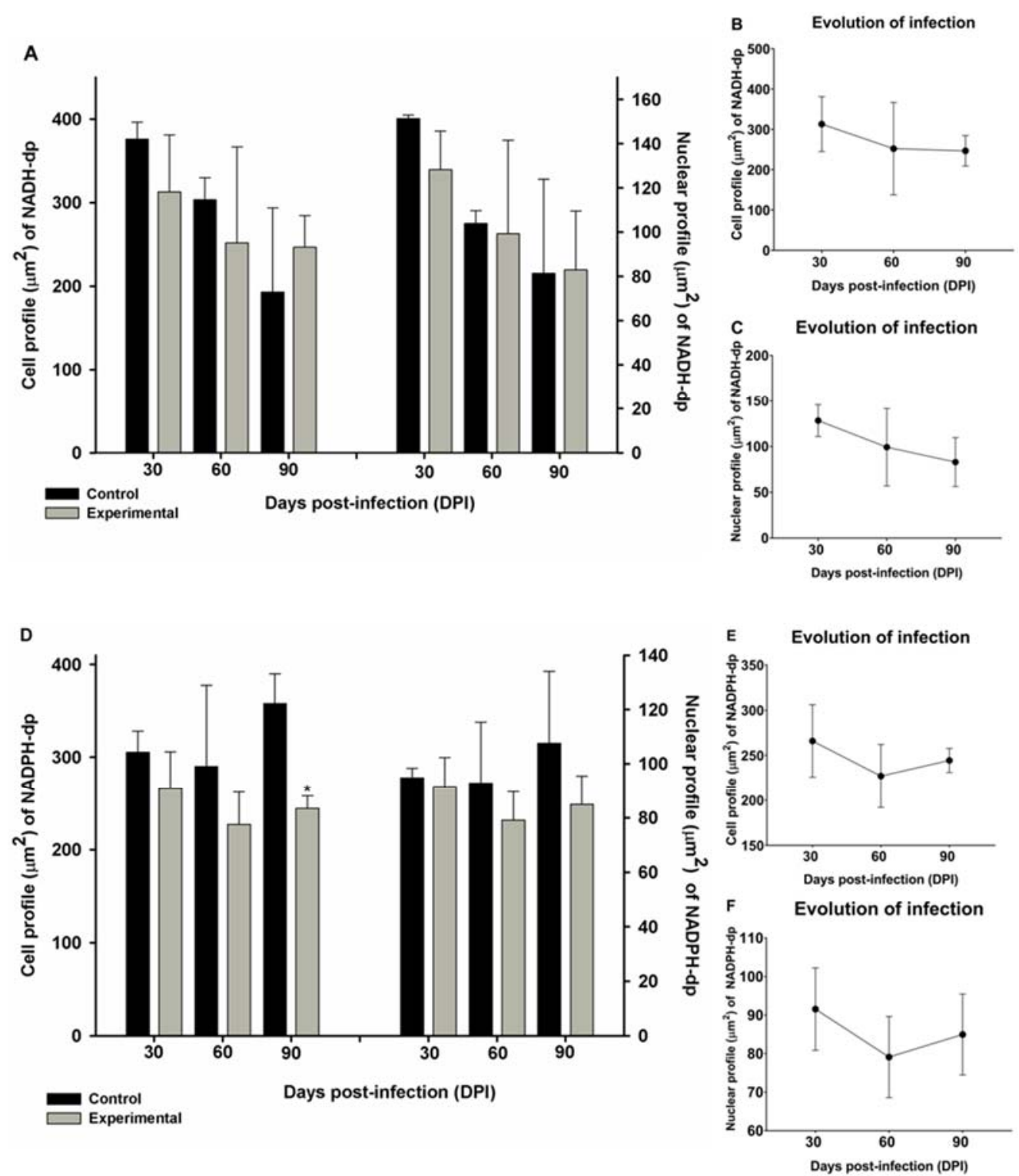

Figure 3. Neuronal morphometry $\left(\mu \mathrm{m}^{2}\right)$ set as cell profile and nuclear profile of NADH-dp (A) and NADPH-dp (D). The changes in cell and nuclear profiles of NADH-dp (B,C), NADPH-dp (E,F) neurons were analyzed during the evolution of $\mathrm{VL}$ infection. ${ }^{*} p<0.05$ between control and experimental groups during the same period of infection.

\subsection{Stratigraphy Evaluation}

The stratigraphic analysis of the jejunum and the quantitative evaluation of intestinal mucosal cells showed the dynamics of the epithelial barrier and the other intestinal layers during the evolution of the infection caused by $L$. (L.) infantum in golden hamsters. At $30 \mathrm{DPI}$, it was possible to record hypertrophic villi in the infected animals related to the control group, but at $60 \mathrm{DPI}$ and $90 \mathrm{DPI}$, the villi became atrophic (Figure 4A). The evaluation of the infection progression showed an alteration in the villus response mechanism through the difference presented statistically at 60 DPI by the infected animals (Figure 4B). Similarly, the crypts in the jejunum of the infected animals were hypertrophic at 30 DPI, but atrophic crypts were observed at 60 DPI and 90 DPI (Figure 4A). In the evolution of the infection, a significant reduction was observed in the depth of crypts at 60 DPI and 90 DPI (Figure 4C). 
A
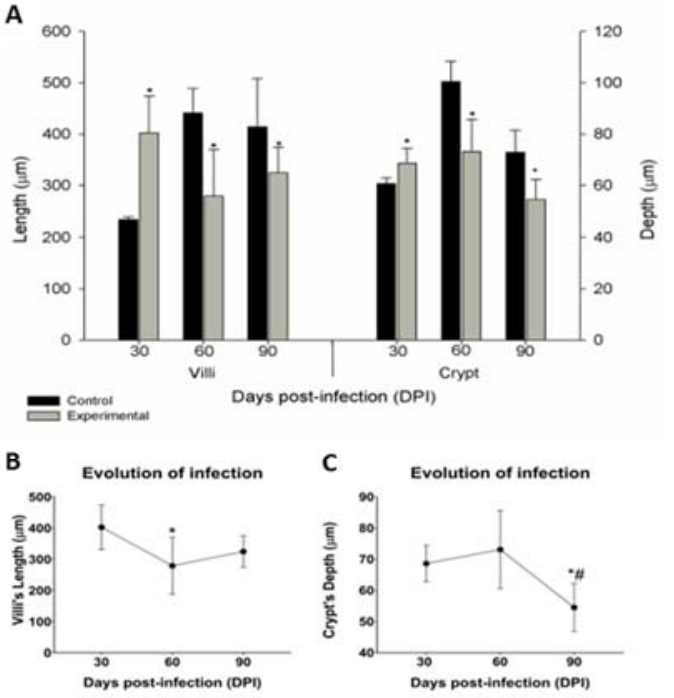

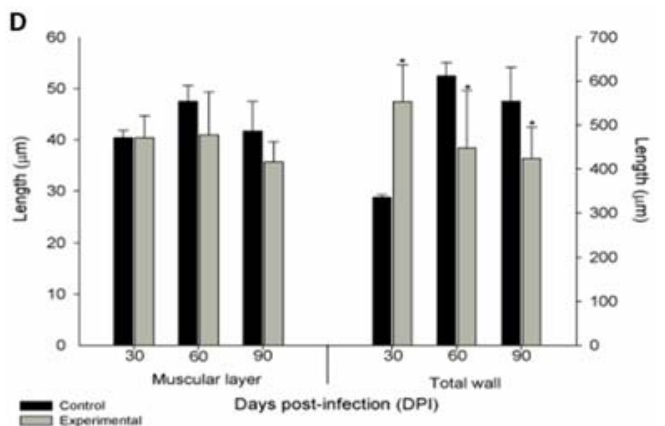

E
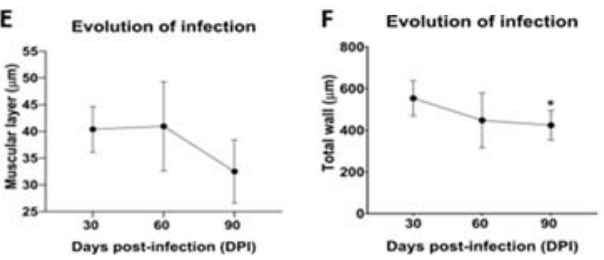

$90 \mathrm{DPI}$

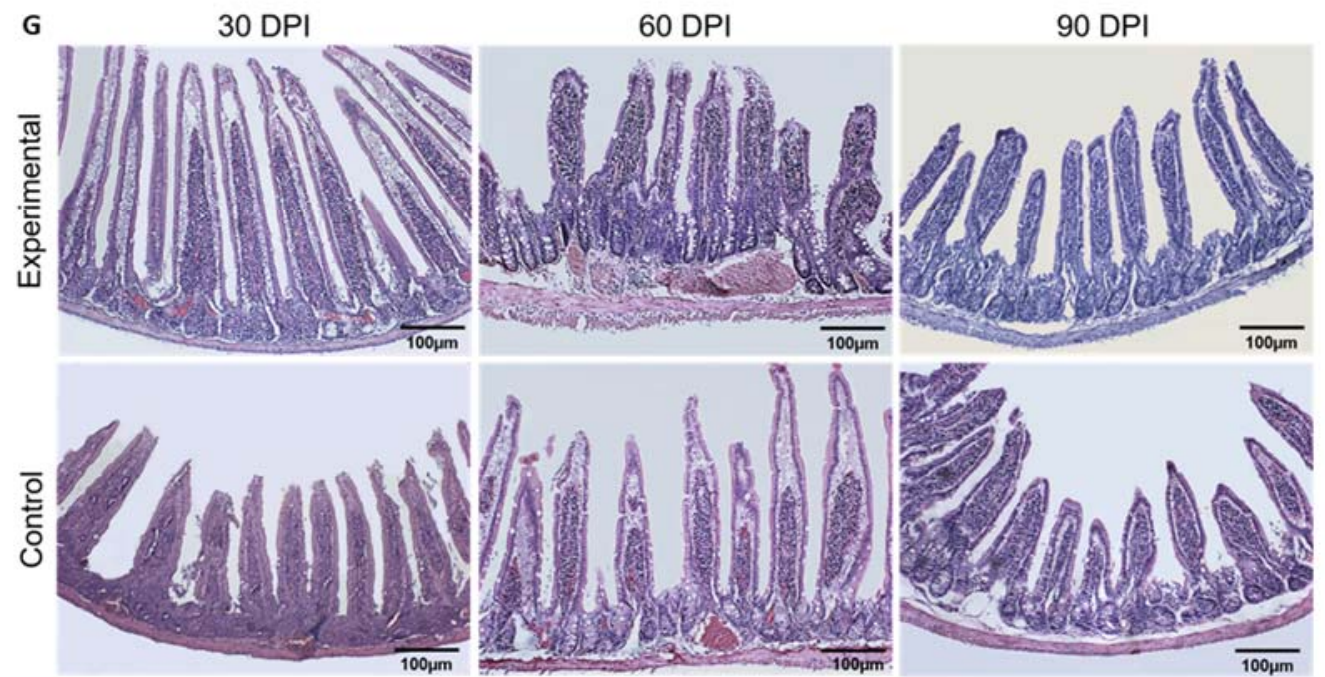

Figure 4. Jejunum stratigraphy set as villus and crypt length (A) and total wall and muscular length (D). Infection evolution of villi (B), crypts (C), muscular layer (E) and total wall (F) length, at 30-, 60-, and 90-days post-infection (DPI) in experimental animals. Photomicrography of total wall of the jejunum (G) of the control and experimental groups, at 30, 60, and 90 days post-infection (DPI). ${ }^{*} p<0.05$, as compared to the 30D PI, and \# $p<0.05$, as compared to the 60 DPI in evolution of infection.

The muscular layer data did not show any significant differences in the comparison between the control and experimental groups (Figure 4D) or in the multiple comparison analysis among the infected animals (Figure 4E). However, in the morphometric analysis, a hypertrophy of the total wall was observed at 30 DPI, but at 60 DPI and 90 DPI, a significant atrophy in this layer was observed (Figure 4D). In the evolution of infection analysis, a statistical difference was observed only at the last period evaluated (90 DPI), as presented in Figure 4F.

\subsection{Mucosa Analysis}

In the mucosa of the jejunum (Table 1), similar densities of PAS+ cells were observed in the control and experimental groups at 30 DPI. However, at $60 \mathrm{DPI}$, a significant reduction of this cell population was observed in the infected animals $(p<0.05)$. The number of goblet cells AB+ were significantly reduced at 30 DPI and 60 DPI in the experimental group in comparison to the control animals, but a significant increase was observed at 90 DPI in the experimental group. Intraepithelial lymphocytes increased during all infection periods 
in comparison to the control group $(p<0.05)$. However, it should be noted that the presence of IELs decreased throughout the evolution of the infection.

Table 1. Ratio between intraepithelial lymphocytes (IEL), Alcian Blue $+(\mathrm{AB}+)$, and Schiff's periodic acid $+(\mathrm{PAS}+)$ goblet cells and enterocytes, expressed as a percentage, of the jejunum during the different periods of infection (30 DPI, 60 DPI, and $90 \mathrm{DPI})$.

\begin{tabular}{ccccc}
\hline Time of Infection & Groups & \multicolumn{3}{c}{ Ratio Cell Type/Enterocyte (\%) } \\
\hline & & PAS+/enterocytes & AB+/Enterocytes & IELs/Enterocytes \\
\hline \multirow{2}{*}{30 DPI } & Control & $2.1 \pm 1.91$ & $7.1 \pm 1.15^{*}$ & $3.7 \pm 0.60^{*}$ \\
& Experimental & $1.35 \pm 0.6$ & $3.5 \pm 0.7^{*}$ & $7.6 \pm 1.8^{*}$ \\
\hline \multirow{2}{*}{60 DPI } & Control & $1.5 \pm 0.3^{*}$ & $5.0 \pm 0.9^{*}$ & $2.0 \pm 1.1^{*}$ \\
& Experimental & $1.0 \pm 0.6^{*}$ & $2.0 \pm 1.3^{*}$ & $4.0 \pm 1.2^{*}$ \\
\hline \multirow{2}{*}{$90 \mathrm{DPI}$} & Control & $3.8 \pm 2.6^{*}$ & $3.9 \pm 2.7^{*}$ & $2.8 \pm 1.2^{*}$ \\
& Experimental & $3.0 \pm 1.9^{*}$ & $6.0 \pm 3.6^{*}$ & $3.0 \pm 1.9^{*}$ \\
\hline
\end{tabular}

$*(p<0.05)$ indicates statistical significance between control and experimental groups in the same period of infection.

\section{Discussion}

Leishmania infection is responsible for compromising the functioning of the main immune organs of the body, and, therefore, the effects of parasitism related to the spleen and the liver have been intensely studied [5-7]. However, research demonstrating the relationship between the Leishmania (L.) infantum infection and the gastrointestinal tract (GIT) have not yet been initiated. In addition, immune cells constantly interact with the GIT in gut-associated lymphoid tissue, and although these areas are important to induce tolerance and eliminate some pathogens, such regions may also represent ideal environments for replication of Leishmania parasites, as has been demonstrated in experimental and natural infections [10,21,33].

Although a few studies analyzed the morphological and neurological changes that take place during protozoal infection, this study detected and analyzed the metabolically active neuronal population (NADH-dp) and the nitrergic subpopulation (NAPH-dp), which have important roles in the fight against parasite infections [34].

In the present study, it was observed that hepatic and splenic parasitism increased with the evolution of the infection, and the same was observed in the jejunum of the infected animals, although the number of parasites in the jejunum was lower in comparison to those in the liver and the spleen. Consistent with our results, studies carried out with natural or experimental infections by Leishmania sp. detected the presence of the protozoan in the intestine $[21,35,36]$, mainly in the submucosal layer, possibly due to the greater vasculature and the higher density of immune cells [37]. Therefore, our study shows that the jejunum can also be infected by $L$. (L.) infantum, and this infection progresses with the evolution of the disease and may possibly cause morphological changes in this organ.

The presence of the amastigote forms did not impact the density of the NADH-dp and NADPH-dp neuronal populations during the evolution of the infection, and that may be associated with the resistance of the nitrergic subpopulations to the parasites, given that the nitrergic populations of neurons produce nitric oxide (NO) that eliminates parasites [38]. In experimental infections caused by Toxoplasma gondii, a high density of nitrergic subpopulations of neurons accumulated in the small intestine, and this was associated with low parasitism. It is possible that NO production ensures the relative control of intracellular parasites and neuroprotection [39-41], which suggests that despite not belonging to the immune cells, nitrergic neurons play a role in the control of parasites.

The reduction in the density and the cellular profile of NADPH-dp neurons observed at 90 DPI is explained by a reduction in the production of the neurotransmitter NO as a compensatory response to the immunity established in the chronic phase of the infection, which was also observed in BALB/c mice infected with Trypanosoma cruzi [42]. Additionally, the presence of high numbers of parasites in the tissue may inhibit the production of $\mathrm{NO}$ 
since this parasite has different antioxidant antigens such as iron superoxide dismutase and tryparedoxin, among others [43-45]. Under normal conditions, the control of GIT motility is mediated by inhibitory neurotransmitters expressing NO through the nitrergic subpopulation and by excitatory neurotransmitters expressing acetylcholine through cholinergic neurons [46]. The decrease in the subpopulation of the NADPH-dp neurons and their atrophy in parasite infections are regularly reported in the literature $[28,30,47]$ and possibly associated with intestinal dysfunctions such as diarrhea [48]. Although diarrhea is not listed as one of the main clinical signs of $\mathrm{VL}$, such as prolonged fever, enlarged spleen and liver, and substantial weight loss [49], many cases have been reported, and although they were associated with bacterial infections [50], diarrhea can sometimes be a symptom related to a late stage of disease [51]. In the present study, a reduction in the density of nitrergic neurons was observed. However, diarrhea was not observed in the infected animals. It is possible that the number of parasites was too small at 90 DPI to induce such clinical symptoms in hamsters.

The results obtained through the analyses of the villi and the crypts showed changes in all periods of infection and indicated that the intestinal mucosa underwent morphological adaptations to maintain intestinal homeostasis [21]. Mucosal hypertrophy was observed at 30 DPI through an increase in the thickness of the villi and the crypts. This occurs because the intestinal infection by Leishmania may initiate in the submucosa [52], promoting an inflammatory response in this layer and accounting for the tissue hypertrophy as well as influencing the thickness of the villi and the crypt in the lamina propria.

Despite a reduction in the density of the $\mathrm{AB}+$ goblet cells, the modifications observed in the jejunum of the infected animals, including the hypertrophy of the crypts and the villi, may also be indicative of increased mitotic activity. The crypts are responsible for producing cells that constitute the intestinal barrier and guide its conformation [12,15]. In addition to the acceleration of cellular turnover, parasite infections can modify the morphology of the barrier and may also stimulate the migration of the intraepithelial lymphocytes to the site of the infection, which also contributes to the increase in the surface of the intestinal mucosa $[32,53,54]$. However, this acceleration in the cell turnover process can negatively influence the differentiation or maturation of pluripotent cells in the crypts [55], which then do not perform their functions correctly, potentially causing barrier disruption leading to events such as inflammatory disorders or result in host susceptibility to intestinal complications [56-58].

At 60 DPI and 90 DPI, atrophy of the mucosal layer was observed as well as atrophy of the thickness of the villi and the crypts. Such changes were associated with the disruption of the intense migration of the intraepithelial lymphocytes, which decreased in intensity throughout the progression of the infection, and fluctuations in the densities of the goblet cell populations. The intestinal barrier integrates immunological and non-immunological components involved in organ defenses against pathogens, wound repair, and interactions with the microbiota and nutrients, effectively participating in homeostatic mechanisms in the intestinal epithelium [56]. Features such as decreased villi and crypts tend to be seen as acquiring an immune tolerance that contributes to the infection chronification process [59,60].

However, a study with Toxoplasma gondii infections in a murine model showing mucosal atrophy indicated that, although there was a reduction in villus and crypt thickness, the cell proliferation and differentiation processes remained active, which suggested that the intestinal barrier kept functioning [29]. Therefore, our results obtained in the 90-day post-infection group may indicate that cell turnover occurred more slowly and selectively to increase the population of $\mathrm{AB}+$ goblet cells. This action may have been a probable attempt to restore the reduced populations at $60 \mathrm{DPI}$ through increased secretion of sialomucins that are essential to restore intestinal homeostasis.

When analyzing the results obtained by morphometric analysis of the tunica muscularis, no significant differences were observed in any of the periods of infection. Unlike these results, the morphometry of the total intestinal wall showed changes during all 
periods of infection, including hypertrophy at 30-days and atrophy at 60- and 90-days postinfection. This suggests that the intestinal barrier is an essential apparatus during the parasite infection caused by Leishmania $(L)$ infantum and promotes changes in its conformation and response mechanisms for the maintenance of homeostasis in the jejunum.

\section{Materials and Methods}

\subsection{Animals and Ethical Considerations}

Golden hamsters (Mesocricetus auratus), 8 weeks old, $250 \mathrm{~g}$ of body weight, were obtained from Anilab (Paulinia, São Paulo, Brazil). This study was carried out in strict accordance with the recommendations of the Guide for the Care and Use of Laboratory Animals of the Brazilian National Council for Animal Experimentation. The protocol was approved by the Ethics Committee of Animal Experiments of the Institutional Committee of Animal Care and Use at the Medical School of São Paulo University (056/16). The hamsters were housed at the Animal Experimental Institute of Tropical Medicine of São Paulo (IMTUSP), according to the standards of the Committee of Animal Welfare and allowed access to food and water ad libitum throughout the study, with a $12 \mathrm{~h}$ light cycle. The animals were anesthetized using intraperitoneal sodium thiopental at $1 \mathrm{mg} / 200 \mu \mathrm{L}$ (Cristália, Brazil).

\subsection{Parasites and Infection}

L. (L.) infantum. (MHOM/BR/72/46) was kindly provided by Prof. Dr. Fernando Tobias Silveira from the cryobank of the Leishmaniasis Laboratory of Prof. Dr. Ralph Laison, Department of Parasitology, Ministry of Health, at the Evandro Chagas Institute (Belém, Pará-Brazil). They were identified using monoclonal antibodies and isoenzyme electrophoretic profiles at the Leishmaniasis Laboratory of the Evandro Chagas Institute. Parasites were maintained in Schneider's medium supplemented with $10 \%$ heat-inactivated fetal bovine serum, $10 \mu \mathrm{g} / \mathrm{mL}$ streptomycin, and $10 \mathrm{IU} / \mathrm{mL}$ ampicillin (ThermoFisher, Waltham, MA, U.S.) (S10). Parasites in late log stage were harvested by centrifugation at $3000 \mathrm{RPM}, 10 \mathrm{~min}, 4^{\circ} \mathrm{C}$, and the pellet was resuspended with PBS.

Thirty golden hamsters were infected with $2 \times 10^{7} \mathrm{~L}$. ( L.) infantum promastigotes by the intraperitoneal route, and thirty were injected with PBS alone by the same route. At 30-, 60-, and 90-days post-infection (DPI), animals in each group were euthanized, and the spleen, the liver and the jejunum were collected.

\subsection{Parasite Load Analysis}

The parasite load in animals infected with $L$. (L.) infantum was analyzed using Leishman-Donovan units. Spleen, liver, and intestine fragments were collected and weighed. Imprints were performed on slides, and after air-drying, they were fixed with methanol and stained with Giemsa. Stained slides were examined under optical microscopy to observe amastigote forms of $L$. (L.) infantum. The results were expressed as the ratio of the number of amastigotes found per 1000 nucleated cells and normalized according to the weight of the respective organ [61].

\subsection{Neuronal Detection}

Fragments of the jejunum from the infected and control groups were stained by histochemistry to identify metabolically active neurons (NADH-dp) and nitrergic neurons (NADPH-dp).

To stain NADH-dp neurons [62], jejunum fragments were washed and filled with Krebs solution (pH 7.3) as well as washed twice in Krebs solution for 10 min. After this step, fragments were incubated in Krebs solution containing 0.3\% Triton X-100 for 5 min, followed by two washes with Krebs solution for $10 \mathrm{~min}$. These fragments were incubated in a sodium-phosphate buffer $(0.1 \mathrm{M}, \mathrm{pH} 7.3)$, containing $0.05 \mathrm{~g}$ of $\beta-\mathrm{NADH}$ in $50 \mathrm{~mL}$ of distilled water, for $45 \mathrm{~min}$. Segments were fixed in a 10\% buffered formalin solution $(0.1 \mathrm{M}$, $\mathrm{pH} 7.3)$. 
After the washing steps (similar to metabolically active neurons), jejunum fragments destined for the histochemical technique of NADPH-dp [63] were incubated in a reaction medium consisting of $50 \mathrm{mg}$ NBT, $100 \mathrm{mg} \beta-\mathrm{NADPH}$, and $0.3 \%$ Triton X-100 in a Tris- $\mathrm{HCl}$ buffer $(0.1 \mathrm{M}, \mathrm{pH} 7.6)$ for $2 \mathrm{~h}$. After these steps, the fragments were fixed in $4 \%$ paraformaldehyde ( $\mathrm{pH} 7.0$ ) solution for fixation and storage.

\subsection{Morpho-Quantitative Analysis of Myenteric Neurons}

After the fixation step, jejunum segments from the infected and control groups were sectioned on the longitudinal axis at the mesenteric margin and microdissected under a stereomicroscope to remove mucosa and submucosa tunics, preserving the muscular and serous tunics. The whole-mount preparations obtained were mounted between glass slides with Permount synthetic resin.

For each membrane preparation, all mesenteric, antimesenteric, and intermediate regions of the jejunum were scanned, and morphometric analyses were performed in at least 40 neuronal ganglia. All neurons in the neuronal ganglion were recorded and quantified. For this analysis, a light microscope (magnification of 100X), coupled with a Motic Image digital camera, was used.

The area of the cell body (CP) and nuclear (NP) profile of myenteric neurons were estimated in at least 100 neurons. Image-Pro Plus 3.0.1 software was used to acquire the images and estimate the area $\left(\mu \mathrm{m}^{2}\right)$ of $\mathrm{CP}$ and NP.

\subsection{Morphometric Analysis of Intestinal Stratigraphy and Quantitative Analysis of Mucosal Cells}

Fragments of approximately three centimeters of the jejunum of the control and infected groups were fixed in $10 \%$ formaldehyde for $48 \mathrm{~h}$. The fragments were washed in $70 \%$ ethyl alcohol, dehydrated in an increasing series of alcohols until absolute (PA), and diaphanized in xylene. The samples were semi-serial sectioned with paraffin at $5 \mu \mathrm{m}$ and stained with hematoxylin and eosin (HE). Morphometric analyzes were performed on the jejunum sections, analyzing (1) the thickness of the tunica muscularis $(\mu \mathrm{m}),(2)$ the total wall of the jejunum $(\mu \mathrm{m})$, and (3) the villus and the crypt height $(\mu \mathrm{m})$. Another batch of histological sections of the jejunum was stained with periodic acid-Schiff (PAS) and Alcian blue (AB) ( $\mathrm{pH} 2.5)$, both counterstained with hematoxylin to analyze the number of enterocytes, PAS+ and AB+ goblet cells, and intraepithelial lymphocytes (IELs) in the mucosal layer. These morphometric analyzes were performed in 12 fields per slide that were chosen at random.

\subsection{Statistical Analysis}

The results obtained were analyzed using GraphPad Prism 8.0, and the control and experimental groups were submitted to the Student's t-test, followed by Tukey's post hoc test. To assess the progression of the infection, the experimental animals were submitted to a one-way ANOVA, where a multiple-comparison test was only performed between infected animals at $30 \mathrm{DPI}, 60 \mathrm{DPI}$, and $90 \mathrm{DPI}$. The results were expressed as mean \pm standard deviation, and the significance level was $5 \%$.

\section{Conclusions}

By analyzing the changes that occurred in the gastrointestinal tracts of hamsters infected with $L$. (L.) infantum for 90 days, it was possible to observe that the most severe changes appeared at the beginning of the infection (30 DPI), where it was possible to record morphological changes in the GIT, such as hypertrophy of the stratigraphic layers and the presence of lymphocytes in the mucosa.

At 60 DPI and 90 DPI, it was possible to observe a trend towards the normalization of the effects of the parasite on the GIT, although alterations in neuronal and GIT stratigraphy could be observed. Thus, we can conclude that infections by L. (L.) infantum can promote changes in the intestinal barrier, such as in the neuronal density and the morphometry of the jejunum in golden hamsters (Mesocricetus auratus). Additionally, it was possible 
to observe that the infection induces different responses during the different periods of infection as the gastrointestinal tract attempts to maintain homeostasis.

Author Contributions: Conceptualization, R.d.B.M., L.F.D.P. and M.D.L.; methodology R.d.B.M., L.F.D.P., S.K.S.d.L., I.N.C., G.P.M., T.M.C., K.S.O., J.A.J. and M.D.L.; formal analysis, R.d.B.M., L.F.D.P. and S.K.S.d.L.; data curation, R.d.B.M., L.F.D.P., S.K.S.d.L., I.N.C., G.P.M., T.M.C., K.S.O., J.A.J. and M.D.L.; writing一review and editing, R.d.B.M., L.F.D.P., S.K.S.d.L., M.D.L. and G.P.M.; supervision, R.d.B.M., L.F.D.P. and M.D.L.; funding acquisition, S.K.S.d.L., I.N.C. and J.A.J. All authors have read and agreed to the published version of the manuscript.

Funding: This research was funded by São Paulo Research Foundation (FAPESP) [processes $\mathrm{n}$. 2019/21557-0, 2018/24077-6, 2018/04869-5, n. 2018/06778-7, n. 2016/00468-0 and 2014/07793-9] and HCFMUSP-LIM50.

Institutional Review Board Statement: Not applicable.

Informed Consent Statement: Not applicable.

Data Availability Statement: The data used to support the findings of this study are included within the article.

Conflicts of Interest: The authors declare no conflict of interest.

\section{References}

1. Akhoundi, M.; Kuhls, K.; Cannet, A.; Votýpka, J.; Marty, P.; Delaunay, P.; Sereno, D. A Historical Overview of the Classification, Evolution, and Dispersion of Leishmania Parasites and Sandflies. PLoS Negl. Trop. Dis. 2016, 10, e0004349. [CrossRef]

2. Wilhelm, T.J. Viszerale Leishmaniose. Der Chir. 2019, 90, 833-837. [CrossRef] [PubMed]

3. World Health Organization. Leishmaniasis. Available online: https://www.who.int/news-room/fact-sheets/detail/ leishmaniasis (accessed on 25 August 2021).

4. Yeshaw, Y.; Tsegaye, A.T.; Nigatu, S.G. Incidence of Mortality and Its Predictors among Adult Visceral Leishmaniasis Patients at the University of Gondar Hospital: A Retrospective Cohort Study. Infect. Drug Resist. 2020, 13, 881. [CrossRef] [PubMed]

5. Baltazar, P.I.; Da Silva, L.M.; Pessoa, G.T.; De Sá, R.P.R.; Sanches, M.P.; Das Neves, A.D.; Das Chagas, F.A.S.; Guerra, P.C.; Neves, W.C.; Giglio, R.F.; et al. Comparative B-Mode and Doppler Renal Ultrasonography with Histopathological Findings in Dogs Positive for Canine Visceral Leishmaniasis. Microsc. Res. Tech. 2016, 79, 637-645. [CrossRef]

6. Lisboa, A.R.; Leite, F.C.; Dantas, A.E.F.; Oliveira, I.B.; Evangelista, T.R.; Sousa, J.B.G. Análise Epidemiológica de Leishmaniose Visceral Em Municípios Do Sertão Paraibano. Rev. Bras. Educ. Saúde 2016, 6, 5. [CrossRef]

7. Marinho, C.P.; Souza, I.M.; Xavier, M.E.B.; Dourisboure, C.J.; Braz, P.H. Achado Citopatológico de Formas Amastigota de Leishmania Spp. Na Língua de Um Canino: Relato de Caso. Pubvet 2017, 11, 1104-1107. [CrossRef]

8. van Griensven, J.; Diro, E. Visceral Leishmaniasis. Infect. Dis. Clin. N. Am. 2012, 26, 309-322. [CrossRef] [PubMed]

9. Silva, C.M.H.S.; Winck, C.A. Leishmaniose Visceral Canina: Revisão de Literatura. Rev. Univ. Val. Rio Verde 2018, 16, 1. [CrossRef]

10. Silva, D.T.D.; Alves, M.L.; Spada, J.C.P.; Silva, A.C.D.; Silveira, R.D.C.V.D.; Oliveira, T.M.F.D.S.; Starke-Buzetti, W.A. T Lymphocytes and Macrophages in the Intestinal Tissues of Dogs Infected with Leishmania Infantum. Rev. Bras. Parasitol. Vet. 2017, 26, 159-170. [CrossRef]

11. Junqueira, L.C.; Carneiro, J. Histologia Básica, 12nd ed.; Guanabara Koogan: Rio de Janeiro, Brazil, 2013.

12. Ross, M.H.; Pawlina, W. Histology: A Text and Atlas, with Correlated Cell and Molecular Biology, 7th ed.; Lippincott Williams \& Wilkins: Philadelphia, PA, USA, 2017.

13. Ahluwalia, B.; Magnusson, M.K.; Öhman, L. Mucosal Immune System of the Gastrointestinal Tract: Maintaining Balance between the Good and the Bad. Scand. J. Gastroenterol. 2017, 52, 1185-1193. [CrossRef]

14. Peterson, L.W.; Artis, D. Intestinal Epithelial Cells: Regulators of Barrier Function and Immune Homeostasis. Nat. Rev. Immunol. 2014, 14, 141-153. [CrossRef]

15. Romero, E.S.; Cotoner, A.C.; Camacho, C.P.; Bedmar, M.C.; Vicario, M. The Intestinal Barrier Function and Its Involvement in Digestive Disease. Rev. Esp. Enferm. Dig. 2015, 107, 686-696. [CrossRef]

16. Lema, I.; Araújo, J.R.; Rolhion, N.; Demignot, S. Jejunum: The Understudied Meeting Place of Dietary Lipids and the Microbiota. Biochimie 2020, 178, 124-136. [CrossRef] [PubMed]

17. Cardoso-Silva, D.; Delbue, D.; Itzlinger, D.; Moerkens, R.; Withoff, S.; Branchi, F.; Schumann, M. Intestinal Barrier Function in Gluten-Related Disorders. Nutrients 2019, 11, 2325. [CrossRef] [PubMed]

18. Camara-Lemarroy, C.R.; Wee Yong, V. The Intestinal Barrier in Multiple Sclerosis: Implications for Pathophysiology and Therapeutics Development of Treatments for Progressive Multiple Sclerosis View Project Remyelination in MS View Project. Brain 2018, 141, 1900-1916. [CrossRef] [PubMed]

19. Mao, X.; Yang, Q.; Chen, D.; Yu, B.; He, J. Benzoic Acid Used as Food and Feed Additives Can Regulate Gut Functions. Biomed Res. Int. 2019, 2019, 5721585. [CrossRef] [PubMed] 
20. He, S.; Kahles, F.; Rattik, S.; Nairz, M.; McAlpine, C.S.; Anzai, A.; Selgrade, D.; Fenn, A.M.; Chan, C.T.; Mindur, J.E.; et al. Gut Intraepithelial T Cells Calibrate Metabolism and Accelerate Cardiovascular Disease. Nature 2019, 566, 115-119. [CrossRef] [PubMed]

21. Figueiredo, M.M.; Deoti, B.; Amorim, I.F.; Pinto, A.J.; Moraes, A.; Carvalho, C.S.; da Silva, S.M.; de Faria, A.M.; Tafuri, W.L. Expression of Regulatory T Cells in Jejunum, Colon, and Cervical and Mesenteric Lymph Nodes of Dogs Naturally Infected with Leishmania Infantum. Infect. Immun. 2014, 82, 3704-3712. [CrossRef]

22. Furness, J.B. The Organisation of the Autonomic Nervous System: Peripheral Connections. Auton. Neurosci. Basic Clin. 2006, 130, 1-5. [CrossRef]

23. Furness, J.B.; Callaghan, B.P.; Rivera, L.R.; Cho, H. The Enteric Nervous System and Gastrointestinal Innervation: Integrated Local and Central Control. Adv. Exp. Med. Biol. 2014, 817, 39-71. [CrossRef]

24. Furness, J.B. The Enteric Nervous System and Neurogastroenterology. Nat. Rev. Gastroenterol. Hepatol. 2012, 9, 286-294. [CrossRef]

25. Boron, W.F.; Boulpaep, E.L. Fisiologia Médica, 4th ed.; Elsevier: Rio de Janeiro, Brazil, 2015.

26. Lomax, A.E.; Fernández, E.; Sharkey, K.A. Plasticity of the Enteric Nervous System during Intestinal Inflammation. Neurogastroenterol. Motil. 2005, 17, 4-15. [CrossRef]

27. Palus, K.; Bulc, M.; Całka, J. Changes in VIP-, SP- and CGRP- like Immunoreactivity in Intramural Neurons within the Pig Stomach Following Supplementation with Low and High Doses of Acrylamide. Neurotoxicology 2018, 69, 47-59. [CrossRef]

28. Machado, C.C.A.; Watanabe, P.S.; Mendes, J.D.L.; Pupim, A.C.E.; Ortigoza, S.M.; Bergoc, H.G.; Nino, B.S.L.; Góis, M.B.; Garcia, J.L.; Blackshaw, L.A.; et al. Toxoplasma Gondii Infection Impairs the Colonic Motility of Rats Due to Loss of Myenteric Neurons. Neurogastroenterol. Motil. 2021, 33, e13967. [CrossRef]

29. Vicentino-Vieira, S.; Góis, M.B.; Trevizan, A.R.; de Lima, L.L.; Leatte, E.P.; Melo, G.A.N.; Garcia, J.L.; Araújo, E.J.A.; Sant'Ana, D.M.G. Toxoplasma Gondii Infection Causes Structural Changes in the Jejunum of Rats Infected with Different Inoculum Doses. Life Sci. 2017, 191, 141-149. [CrossRef] [PubMed]

30. Sant'Ana, D.M.G.; Gois, M.B.; Hermes-Uliana, C.; Pereira-Severi, L.S.; Baptista, E.M.; Mantovani, L.C.; da Silva, A.V.; Araújo, E.J.A. Acute Infection with an Avirulent Strain of Toxoplasma Gondii Causes Decreasing and Atrophy of Nitrergic Myenteric Neurons of Rats. Acta Histochem. 2017, 119, 423-427. [CrossRef] [PubMed]

31. dos Santos, A.G.A.; da Silva, M.G.L.; Carneiro, E.L.; de Lima, L.L.; Fernandes, A.C.B.S.; Silveira, T.G.V.; Sant'Ana, D.d.M.G.; Nogueira-Melo, G.d.A. A New Target Organ of Leishmania (Viannia) Braziliensis Chronic Infection: The Intestine. Front. Cell. Infect. Microbiol. 2021, 11. [CrossRef]

32. Santos, A.G.A.D.; Lima, L.L.; Mota, C.A.; Gois, M.B.; Fernandes, A.C.B.S.; Silveira, T.G.V.; Sant'Ana, D.M.G.; de Melo, G.A.N. Insights of Leishmania (Viannia) Braziliensis Infection in Golden Hamster (Mesocricetus Auratus) Intestine. Biomed. Pharmacother. 2018, 106, 1624-1632. [CrossRef] [PubMed]

33. Casanova, M.I.; Martín, S.; Marco, A.; Solano-Gallego, L. Detection of Leishmania Spp. Infection by Immunohistochemistry in Archived Biopsy Samples from Dogs with Colitis in an Area Endemic for Leishmaniosis. J. Comp. Pathol. 2019, $167,12-17$. [CrossRef]

34. Halliez, M.C.M.; Buret, A.G. Gastrointestinal Parasites and the Neural Control of Gut Functions. Front. Cell. Neurosci. 2015, 9, 452. [CrossRef]

35. Santos, A.G.A.D.; Ferlini, J.P.; Vicentino, S.L.; Lonardoni, M.V.; Sant'Ana, D.M.G.; Melo, G.A.N. Alterations Induced in the Ileum of Mice upon Inoculation with Different Species of Leishmania: A Preliminary Study. Rev. Soc. Bras. Med. Trop. 2018, 51, 537-541. [CrossRef] [PubMed]

36. Silva, D.T.D.; Alves, M.L.; Spada, J.C.P.; Silveira, R.C.V.D.; Oliveira, T.M.F.S.; Starke-Buzetti, W.A. Neutrophils, Eosinophils, and Mast Cells in the Intestinal Wall of Dogs Naturally Infected with Leishmania Infantum. Rev. Bras. Parasitol. Vet. 2018, $27,430-438$. [CrossRef]

37. Lewis, M.D.; Paun, A.; Romano, A.; Langston, H.; Langner, C.A.; Moore, I.N.; Bock, K.W.; Francisco, A.F.; Brenchley, J.M.; Sacks, D.L. Fatal Progression of Experimental Visceral Leishmaniasis Is Associated with Intestinal Parasitism and Secondary Infection by Commensal Bacteria, and Is Delayed by Antibiotic Prophylaxis. PLoS Pathog. 2020, 16, e1008456. [CrossRef]

38. Hermes-Uliana, C.; Pereira-Severi, L.S.; Luerdes, R.B.; Franco, C.L.M.; da Silva, A.V.; Araújo, E.J.d.A.; Sant'Ana, D.d.M.G. Chronic Infection with Toxoplasma Gondii Causes Myenteric Neuroplasticity of the Jejunum in Rats. Auton. Neurosci. Basic Clin. 2011, 160, 3-8. [CrossRef]

39. Odorizzi, L.; Moreira, N.M.; Gonçalves, G.F.; da Silva, A.V.; Sant'Ana, D.d.M.G.; Araújo, E.J.d.A. Quantitative and Morphometric Changes of Subpopulations of Myenteric Neurons in Swines with Toxoplasmosis. Auton. Neurosci. Basic Clin. 2010, 155, 68-72. [CrossRef]

40. Vicentino-Vieira, S.L.; Nogueira de Melo, G.d.A.; Biondaro Góis, M.; Martins Moreira, N.; de Araujo Pereira, L.G.; de Almeida Araújo, E.J.; Garcia, J.L.; de Mello Gonçales Sant'Ana, D. Oral Dependent-Dose Toxoplasmic Infection Model Induced by Oocysts in Rats: Myenteric Plexus and Jejunal Wall Changes. Exp. Parasitol. 2015, 156, 12-18. [CrossRef]

41. Ferezin, R.I.; Vicentino-Vieira, S.L.; Góis, M.B.; Araújo, E.J.D.A.; de Melo, G.D.A.N.; Garcia, J.L.; Sant'Ana, D.D.M.G. Diferentes Inóculos de Toxoplasma Gondii Induzem a Redução de Neurônios Mioentéricos No Cólon de Ratos. Rev. Bras. Parasitol. Vet. 2017, 26, 47-53. [CrossRef] [PubMed] 
42. Oda, J.Y.; Belém, M.O.; Carlos, T.M.; Gouveia, R.; Luchetti, B.F.C.; Moreira, N.M.; Massocatto, C.L.; Araújo, S.M.; Sant'Ana, D.M.G.; Buttow, N.C.; et al. Myenteric Neuroprotective Role of Aspirin in Acute and Chronic Experimental Infections with Trypanosoma Cruzi. Neurogastroenterol. Motil. 2017, 29, 1-13. [CrossRef]

43. Campos, B.L.S.; Silva, T.N.; Ribeiro, S.P.; Carvalho, K.I.L.; Kallás, E.G.; Laurenti, M.D.; Passero, L.F.D. Analysis of Iron Superoxide Dismutase-Encoding DNA Vaccine on the Evolution of the Leishmania Amazonensis Experimental Infection. Parasite Immunol. 2015, 37, 407-416. [CrossRef]

44. Angiulli, G.; Lantella, A.; Forte, E.; Angelucci, F.; Colotti, G.; Ilari, A.; Malatesta, F. Leishmania Infantum Trypanothione Reductase Is a Promiscuous Enzyme Carrying an NADPH:O2 Oxidoreductase Activity Shared by Glutathione Reductase. Biochim. Biophys. Acta-Gen. Subj. 2015, 1850, 1891-1897. [CrossRef] [PubMed]

45. Fialho Junior, L.; da Fonseca Pires, S.; Burchmore, R.; McGill, S.; Weidt, S.; Ruiz, J.C.; Guimarães, F.G.; Chapeourouge, A.; Perales, J.; de Andrade, H.M. Proteomic Analysis Reveals Differentially Abundant Proteins Probably Involved in the Virulence of Amastigote and Promastigote Forms of Leishmania Infantum. Parasitol. Res. 2021, 120, 679-692. [CrossRef]

46. Liberti, E.A.; Fontes, R.B.V.; Fuggi, V.M.; Maifrino, L.B.M.; Souza, R.R. Effects of Combined Pre- and Post-Natal Protein Deprivation on the Myenteric Plexus of the Esophagus of Weanling Rats: A Histochemical, Quantitative and Ultrastructural Study. World J. Gastroenterol. 2007, 13, 3598. [CrossRef]

47. Trevizan, A.R.; Schneider, L.C.L.; Araújo, E.J.A.; Garcia, J.L.; Buttow, N.C.; Nogueira-Melo, G.A.; Sant'Ana, D.M.G. Acute Toxoplasma Gondii Infection Alters the Number of Neurons and the Proportion of Enteric Glial Cells in the Duodenum in Wistar Rats. Neurogastroenterol. Motil. 2019, 31, e13523. [CrossRef]

48. Karaus, M.; Sarna, S.K. Giant Migrating Contractions during Defecation in the Dog Colon. Gastroenterology 1987, 92, 925-933. [CrossRef]

49. Drugs for Neglected Diseases Initiative Leishmaniasis. Available online: https://dndi.org/diseases/visceral-leishmaniasis/facts / (accessed on 25 August 2021).

50. Costa, C.H.; Werneck, G.L.; Costa, D.L.; Holanda, T.A.; Aguiar, G.B.; Carvalho, A.S.; Cavalcanti, J.C.; Santos, L.S. Is Severe Visceral Leishmaniasis a Systemic Inflammatory Response Syndrome? A Case Control Study. Rev. Soc. Bras. Med. Trop. 2010, 43, 386-392. [CrossRef] [PubMed]

51. Henke, O.; Mapendo, P.J.; Mremi, A.; Mmbaga, L.G.; Pallangyo, A.E.; Harbaum, T.; Mkwizu, E. Skin Maculae, Chronic Diarrhea, Cachexia, and Splenomegaly_Late Presentation of the First Autochthonous Case of Visceral Leishmaniasis in Tanzania. PLoS Negl. Trop. Dis. 2021, 15, e0008925. [CrossRef] [PubMed]

52. Silva, D.T.; Neves, M.F.; Queiroz, N.M.G.P.; Spada, J.C.P.; Alves, M.L.; Silva, M.F.; Coelho, W.M.D.; Panosso, A.R.; Noronha, A.C.F.; Starke-Buzetti, W.A. Correlation Study and Histopathological Description of Intestinal Alterations in Dogs Infected with Leishmania Infantum. Rev. Bras. Parasitol. Veterinária 2016, 25, 24-36. [CrossRef]

53. Trevizan, A.R.; Vicentino-Vieira, S.L.; da Silva, P.W.; Góis, M.B.; de Melo, A.G.; Garcia, J.L.; Araújo, E.J.A.; Sant'Ana, D.M.G. Kinetics of Acute Infection with Toxoplasma Gondii and Histopathological Changes in the Duodenum of Rats. Exp. Parasitol. 2016, 165, 22-29. [CrossRef]

54. Souza, K.D.; Fernandes, E.P.A.; Dos Santos, A.G.A.; de Lima, L.L.; Gonzaga, W.F.K.M.; Xander, P.; Nogueira-Melo, G.A.; Sant'Ana, D.M.G. Infection by Leishmania (Leishmania) Infantum Chagasi Causes Intestinal Changes B-1 Cells Dependent. Parasite Immunol. 2019, 41, e12661. [CrossRef]

55. Abbas, A.K.; Kumar, V.; Aster, J.C. Bases Patológicas Das Doenças, 9th ed.; Elsevier: Rio de Janeiro, Brazil, 2016.

56. Esterházy, D.; Mucida, D. Gut Immune Cells Have a Role in Food Metabolism. Nature 2019, 566, 49-50. [CrossRef]

57. Farhadi, A.; Banan, A.; Fields, J.; Keshavarzian, A. Intestinal Barrier: An Interface between Health and Disease. J. Gastroenterol. Hepatol. 2003, 18, 479-497. [CrossRef] [PubMed]

58. Schneeman, B.O. Gastrointestinal Physiology and Functions. Br. J. Nutr. 2002, 88 (Suppl. 2), S159-S163. [CrossRef] [PubMed]

59. da Silva, J.M.; da Silva, A.V.; Araújo, E.J.A.; Sant'Ana, D.M.G. The Effects of the Infection Caused by Toxoplasma Gondii on the Cat Duodenal Wall. Rev. Bras. Parasitol. Vet. 2010, 19, 57-63. [CrossRef]

60. Shiraishi, C.S.; Azevedo, J.F.; Silva, A.V.; Sant'Ana, D.M.G.; Araújo, E.J.A. Análise Morfométrica Da Parede Intestinal e Dinâmica de Mucinas Secretadas No Íleo de Frangos Infectados Por Toxoplasma Gondii. Ciência Rural 2009, 39, 2146-2153. [CrossRef]

61. Stauber, L. Leishmaniasis in the Hamster. In Some Physiological Aspects and Consequences of Parasitism; Cole, W.H., Ed.; Rutgers University Press: New Brunswisck, NJ, USA, 1955.

62. Gabella, G. Detection of Nerve Cells by a Histochemical Technique. Experientia 1969, 25, 218-219. [CrossRef] [PubMed]

63. Scherer-Singler, U.; Vincent, S.R.; Kimura, H.; McGeer, E.G. Demonstration of a Unique Population of Neurons with NADPHDiaphorase Histochemistry. J. Neurosci. Methods 1983, 9, 229-234. [CrossRef] 